\title{
Outcomes of excimer laser enhancements in pseudophakic patients with multifocal intraocular lens
}

This article was published in the following Dove Press journal:

Clinical Ophthalmology

27 April 2016

Number of times this article has been viewed

\author{
Steven C Schallhorn ${ }^{1-3}$ \\ Jan A Venter ${ }^{2}$ \\ David Teenan ${ }^{2}$ \\ Julie M Schallhorn ${ }^{3}$ \\ Keith A Hettinger ${ }^{2}$ \\ Stephen J Hannan ${ }^{2}$ \\ Martina Pelouskova ${ }^{2}$ \\ 'Department of Ophthalmology, \\ University of California, San Francisco, \\ CA, USA; ${ }^{2}$ Optical Express, Glasgow, \\ UK; ${ }^{3}$ Department of Ophthalmology, \\ University of Southern California, Los \\ Angeles, CA, USA
}

\begin{abstract}
Purpose: The aim of this study was to assess visual and refractive outcomes of laser vision correction (LVC) to correct residual refraction after multifocal intraocular lens (IOL) implantation.
\end{abstract}

Patients and methods: In this retrospective study, 782 eyes that underwent LVC to correct unintended ametropia after multifocal IOL implantation were evaluated. Of all multifocal lenses implanted during primary procedure, $98.7 \%$ were refractive and $1.3 \%$ had a diffractive design. All eyes were treated with VISX STAR S4 IR excimer laser using a convectional ablation profile. Refractive outcomes, visual acuities, patient satisfaction, and quality of life were evaluated at the last available visit.

Results: The mean time between enhancement and last visit was $6.3 \pm 4.4$ months. Manifest spherical equivalent changed from $-0.02 \pm 0.83 \mathrm{D}(-3.38 \mathrm{D}$ to $+2.25 \mathrm{D})$ pre-enhancement to $0.00 \pm 0.34 \mathrm{D}(-1.38 \mathrm{D}$ to $+1.25 \mathrm{D})$ post-enhancement. At the last follow-up, the percentage of eyes within $0.50 \mathrm{D}$ and $1.00 \mathrm{D}$ of emmetropia was $90.4 \%$ and $99.5 \%$, respectively. Of all eyes, $74.9 \%$ achieved monocular uncorrected distance visual acuity $20 / 20$ or better. The mean corrected distance visual acuity remained the same before $(-0.04 \pm 0.06 \log$ MAR [logarithm of the minimum angle of resolution] $)$ and after LVC procedure $(-0.04 \pm 0.07 \operatorname{logMAR} ; P=0.70)$. There was a slight improvement in visual phenomena (starburst, halo, glare, ghosting/double vision) following the enhancement. No sight-threatening complications related to LVC occurred in this study.

Conclusion: LVC in pseudophakic patients with multifocal IOL was safe, effective, and predictable in a large cohort of patients.

Keywords: excimer laser enhancements, pseudophakic patients, multifocal IOL

\section{Introduction}

Cataract surgery is one of the most commonly performed ophthalmic procedures in the world. In modern ophthalmology, phacoemulsification with intraocular lens (IOL) implantation is becoming more of a refractive procedure with patients having higher expectations and seeking spectacle independence. Despite advances in IOL formulas and surgical and biometric techniques, unintended postoperative ametropia cannot be always eliminated. Common causes of undesired refractive error include inaccuracies in preoperative measurements or biometric calculations, ${ }^{1-3}$ variations in lens formulas, ${ }^{4,5}$ incorrect selection of IOL power, ${ }^{6}$ manufacturing precision, or postoperative positional changes. ${ }^{1,6}$

Established surgical techniques to rectify refractive error after IOL implantation are excimer laser surgery, ${ }^{7-18}$ astigmatic keratectomy, ${ }^{19}$ IOL exchange, ${ }^{19-23}$ and an
Correspondence: Steven C Schallhorn Gordon Schanzlin New Vision Institute, 8910 University Center Lane, Suite 800, San Diego, CA 92122, USA

Tel +l 8584556800

Email scschallhorn@yahoo.com 
implantation of a piggyback IOL. ${ }^{19-23}$ Laser in situ keratomileusis (LASIK) or photorefractive keratectomy (PRK) were found to be the most accurate and safest surgical options for pseudophakic ametropia, ${ }^{19-23}$ with other techniques (IOL exchange or secondary IOL) being used mainly in the cases of higher ametropia or in eyes where excimer laser ablation is contraindicated.

In patients with multifocal IOLs, postoperative refractive error can possibly exacerbate problems inherent to these lens designs, such as loss of contrast sensitivity or photic phenomena, resulting in higher postoperative dissatisfaction. ${ }^{24,25}$ Some reports also suggest that surgical correction of refractive error in eyes with multifocal IOL might be technically more difficult. ${ }^{16,17}$ This is due to difficulties in estimating refractive error caused by increased depth of focus and split of light to several foci in multifocal designs, ${ }^{16,17}$ as well as problems associated with measuring refractive error by automated devices ${ }^{26}$ or estimation of higher-order aberration with Hartmann-Shack aberrometers if wavefront-guided (WFG) treatment is intended. ${ }^{27,28}$

To date, only a few reports have been published on clinical outcomes of LASIK/PRK in pseudophakic patients implanted with multifocal IOLs, ${ }^{11,13-17}$ with small numbers of patients involved. The aim of this study was to present predictability, safety, and efficacy of excimer laser correction for undesired ametropia in pseudophakic patients implanted with multifocal IOLs in a large cohort of patients.

\section{Patients and methods}

A retrospective data review was performed to identify patients who had excimer laser retreatment for residual ametropia following the primary cataract/refractive lens exchange with an implantation of a multifocal IOL between December 2013 and June 2015. The study was deemed exempt from full review by the Committee of Human Research at the University of California, San Francisco, because it used only the retrospective, de-identified patient data. Written informed consent to undergo primary and enhancement procedure was obtained from all patients.

A total of 782 eyes of 576 patients were included in this study. Criteria for retreatment were that patients were unhappy with some aspect of their vision (either blurred distant and/ or near vision or visual symptoms) that was related to their residual refractive error and an in-clinic demonstration using trial frames improved their symptoms. If there was any doubt about eligibility for enhancement, patients underwent a contact lens or spectacle trial for several days to demonstrate whether the gain in near/distance vision would warrant a surgical procedure. In addition, they had to have a stable manifest refraction of no more than a $0.50 \mathrm{D}$ change in either sphere or cylinder, documented over a minimum of 3 months. Only patients with a follow-up of 1 month or more postenhancement were included in this study. Exclusion criteria for enhancement were active ophthalmic diseases, presence of posterior capsular opacification, abnormal corneal shape, concurrent medications, or medical conditions that could impair healing and a calculated residual stromal bed $<250 \mu \mathrm{m}$.

Ophthalmic examination prior to the initial procedure included manifest and cycloplegic refraction, uncorrected distance visual acuity (UDVA), corrected distance visual acuity (CDVA), uncorrected near visual acuity (UNVA), slitlamp evaluation, dilated fundoscopy, autorefraction and tonometry (Tonoref II; Nidek Co. Ltd., Gamagori, Japan), corneal topography (Pentacam; Oculus, Inc., Wetzlar, Germany), endothelial cell count (SP-2000P specular microscope; Topcon Europe BV, Newbury, UK), biometry (IOLMaster; Carl Zeiss Meditec AG, Jena, Germany), and retinal optical coherence tomography (Cirrus 4000 OCT; Carl Zeiss Meditec AG). Visual acuity was measured at distance using a Snellen visual acuity chart and close-up using a logarithmic near visual acuity chart (the Early Treatment Diabetic Retinopathy Study) at $40 \mathrm{~cm}$. Near visual acuity was recorded in Snellen distance equivalent (meters). Biometry (IOLMaster) was used for lens calculation and surgeon preference determined the choice of IOL formula. Generally, Haigis or Holladay II formulas were used in most cases, and other formulas (such as Hoffer-Q and SRK/T) were considered in eyes with extreme axial lengths. All eyes were targeted for emmetropia.

The same examinations as prior to initial procedure were carried out prior to enhancement, excluding cycloplegic refraction and biometry. All patients were advised to return for follow-up at 1 day, 4 days (surface ablation only), 1 week, 1 month, and 3 months and thereafter as required. The data of the last available postoperative visit are presented in this study. Manifest refraction, UDVA, UNVA, CDVA, and slitlamp examinations were performed postoperatively.

All patients were asked to complete a questionnaire during their postoperative visits. It was self-administered by the patient using a password protected and secure computer terminal in an isolated area of the clinic. The questionnaire responses were stored in the secured Optical Express central database, which is compliant with ISO 27001 for information security management systems. The questionnaire was derived from the Joint LASIK Study Task Force. ${ }^{29}$ Patients were asked to rate their satisfaction with visual acuity as well as difficulty with night vision phenomena and various tasks that require close-up or distance vision (Figure 1). The last available 
prednisolone acetate $1 \%$ four times a day for 1 week, and preservative-free artificial tear drops.

In eyes having surface ablation, the eye was topically anesthetized and a $9 \mathrm{~mm}$ well was placed on the cornea and filled with $20 \%$ ethanol. Following a 30-40-second application, the alcohol was drained with a surgical spear and the eye was irrigated with a balanced salt solution. The epithelium was removed with a blunt spatula, the programmed treatment was applied, and a bandage contact lens was placed on the eye and left in place until the cornea was re-epithelialized. Postoperative medication consisted of topical levofloxacin $0.5 \%$, four times a day for 1 week, and 4 weeks of a tapering dose of topical fluorometholone ophthalmic solution $0.1 \%$ in the following sequence: four times a day for 1 week, three times a day for 1 week, two times a day for 1 week, and once a day for 1 week.

Excimer laser enhancements were performed with a conventional ablation profile using VISX STAR S4 IR excimer laser (Abbott Medical Optics Inc.). Treatment was based on patient's manifest refraction, and nomogram adjustment was applied based on the previous experience with conventional ablations on primary laser vision correction (LVC) cases.

For myopic treatments, the optical zone (OZ) diameter was $6.5 \mathrm{~mm}$; for myopic astigmatism, the major axis of the elliptical OZ was $6.5 \mathrm{~mm}$ with a minor axis as small as $5.0 \mathrm{~mm}$ depending on the amount of myopia and astigmatism. The transition zone was $8 \mathrm{~mm}$, unless there was $<1.0 \mathrm{D}$ of myopia. Hyperopic treatments had $6.0 \mathrm{~mm} \mathrm{OZ}$ and $9.0 \mathrm{~mm}$ transition zone. LASIK was the preferred enhancement procedure, which was performed on $91.2 \%$ of eyes. Where clinical parameters (such as corneal pachymetry and topography) did not allow creation of LASIK flap, PRK was performed ( $8.8 \%$ of eyes).

\section{Statistical analysis}

Normality of data samples was evaluated by the KolmogorovSmirnov test. When normality condition could be assumed, paired Student's $t$-test was used to compare preoperative and postoperative data. When parametric analysis was not possible, Wilcoxon rank sum test was applied in place of paired $t$-test. To compare independent groups of patients, unpaired $t$-test or Mann-Whitney $U$-test were used, depending on the normality of data sample. Chi-square test was used to compare percentages. Correlation coefficients were calculated to find the association between questionnaire responses and clinical parameters. All the data were analyzed using Microsoft Office Excel 2007 program (Microsoft Corporation, Redmond, WA, USA) and STATISTICA (StatSoft Inc., Tulsa, OK, USA) on a personal computer. A $P$-value of 0.05 was considered statistically significant.

\section{Results}

A total of 782 eyes of 576 patients were analyzed in this study. The mean age at the time of enhancement was $57.4 \pm 7.2$ years (range: 34-76 years). The mean time from IOL surgery to enhancement was $7.4 \pm 2.5$ months. Of all patients, $266(46.2 \%)$ were females, and $310(53.8 \%)$ were males. Table 1 presents the lens designs implanted during primary cataract/refractive lens exchange procedure. A majority of eyes (98.7\%) were implanted with IOLs with a segmental refractive design. The initial data (prior to intraocular procedure) and pre- and postenhancement data are summarized in Table 2.

Figure 2 shows the distribution of pre- and postenhancement manifest spherical equivalent (MSE). Prior to laser enhancement, $41.2 \%$ of eyes were within $0.50 \mathrm{D}$ and $84.7 \%$ were within 1.00 D of MSE. Post-enhancement, the percentage of eyes within $0.50 \mathrm{D}$ and $1.00 \mathrm{D}$ of emmetropia was $90.4 \%$ and $99.5 \%$, respectively. The reduction in the mean refractive sphere and cylinder was statistically significant (Table 2). A linear regression of attempted preenhancement vs achieved post-enhancement MSE correction (Figure 3) had a slope of 1.06 and intercept of 0.002 .

Figure 4 depicts the cumulative monocular UDVA prior to primary procedure, prior to enhancement, and postenhancement. Prior to enhancement, $2.3 \%$ of patients had

Table I Multifocal lens types implanted during primary cataract/refractive lens exchange procedure

\begin{tabular}{lll}
\hline IOL model (manufacturer) & IOL technology & Number of eyes (\%) \\
\hline Lentis Mplus LS-3I3 MF30 (Oculentis GmbH) & Refractive, nonrotational symmetric & $40 I(5 I .3)$ \\
Lentis Mplus toric LU-3I3 MF30T (Oculentis GmbH) & Refractive, nonrotational symmetric (toric) & $65(8.3)$ \\
Lentis Mplus ${ }^{\times}$LS-3I3 MF30 (Oculentis GmbH) & Refractive, nonrotational symmetric & $213(27.2)$ \\
Lentis Mplus toric LU-3I3 MF30T (Oculentis GmbH) & Refractive, nonrotational symmetric (toric) & $29(3.7)$ \\
Lentis Mplus LS-3I3 MFI5 (Oculentis GmbH) & Refractive, nonrotational symmetric & $20(2.6)$ \\
Lentis Mplus LS-3I3 MF20 (Oculentis GmbH) & Refractive, nonrotational symmetric & $14(1.8)$ \\
SBL-3 (Lenstec, Inc.) & Refractive, nonrotational symmetric & $30(3.8)$ \\
FineVision (PhysIOL S.A.) & Diffractive trifocal & $9(I .2)$ \\
Tecnis ZMB00 (Abbott Medical Optics Inc.) & Diffractive & $1(0.1)$ \\
\hline
\end{tabular}

Abbreviation: IOL, intraocular lens. 
Table 2 Refractive and visual outcomes ( $\mathrm{N}=782$ eyes)

\begin{tabular}{|c|c|c|c|c|}
\hline & $\begin{array}{l}\text { Prior to cataract/refractive } \\
\text { lens exchange }\end{array}$ & $\begin{array}{l}\text { Prior to } \\
\text { enhancement }\end{array}$ & Last visit & $\begin{array}{l}P \text {-value pre- to } \\
\text { post-enhancement }\end{array}$ \\
\hline Sphere (D), mean \pm SD (range) & $+1.08 \pm 3.05(-18.75$ to +9.0$)$ & $\begin{array}{l}+0.42 \pm 0.83 \\
(-3.00 \text { to }+2.50)\end{array}$ & $\begin{array}{l}+0.15 \pm 0.35 \\
(-1.25 \text { to }+1.50)\end{array}$ & $<0.01$ \\
\hline Cylinder (D), mean \pm SD (range) & $-0.84 \pm 0.86(-7.00$ to 0.00$)$ & $\begin{array}{l}-0.87 \pm 0.55 \\
(-4.00 \text { to } 0.00)\end{array}$ & $\begin{array}{l}-0.29 \pm 0.33 \\
(-1.50 \text { to } 0.00)\end{array}$ & $<0.01$ \\
\hline MSE (D), mean \pm SD (range) & $+0.66 \pm 3.09(-19.38$ to +8.50$)$ & $\begin{array}{l}-0.02 \pm 0.83 \\
(-3.38 \text { to }+2.25)\end{array}$ & $\begin{array}{l}0.00 \pm 0.34 \\
(-1.38 \text { to }+1.25)\end{array}$ & 0.52 \\
\hline UDVA (logMAR), mean \pm SD (range) & $0.56 \pm 0.43(-0.08$ to 1.60$)$ & $\begin{array}{l}0.20 \pm 0.15 \\
(-0.08 \text { to } 1.00)\end{array}$ & $\begin{array}{l}0.00 \pm 0.10 \\
(-0.18 \text { to } 0.70)\end{array}$ & $<0.01$ \\
\hline CDVA (logMAR), mean \pm SD (range) & $-0.04 \pm 0.08(-0.18$ to 0.70$)$ & $\begin{array}{l}-0.04 \pm 0.06 \\
(-0.18 \text { to } 0.30)\end{array}$ & $\begin{array}{l}-0.04 \pm 0.07 \\
(-0.18 \text { to } 0.70)\end{array}$ & 0.70 \\
\hline Follow-up (months) & Primary to enhancement $7.4 \pm 2.5$ & \multicolumn{3}{|c|}{ Enhancement to last visit $6.3 \pm 4.4$} \\
\hline
\end{tabular}

Abbreviations: CDVA, corrected distance visual acuity; D, diopter; logMAR, logarithm of the minimum angle of resolution; MSE, manifest spherical equivalent; UDVA, uncorrected distance visual acuity.

UDVA $20 / 16$ or better and $7.8 \% 20 / 20$ or better. These were mostly eyes with low amount of hyperopia or mixed astigmatism, where the small amount of refractive error affected the multifocal performance of the IOL. The percentage of eyes achieving 20/16 or 20/20 or better UDVA post-enhancement was $39.4 \%$ and $74.9 \%$, respectively. Binocularly, $44.1 \%$ of patients had UDVA $20 / 20$ or better prior to enhancement and $92.0 \%$ post-enhancement. Figure 5 shows the cumulative UNVA. The percentage of patients achieving monocular UNVA $20 / 40$ (J5) or better was $61.3 \%$ prior to enhancement and $76.6 \%$ post-enhancement. Binocularly, $75.8 \%$ and $86.6 \%$ of patients achieved $20 / 40$ UNVA pre- and postenhancement, respectively.

Figure 6 shows the comparison of pre-enhancement CDVA to post-enhancement CDVA. The mean change in
CDVA was not statistically significant (Table 2). The loss of two lines of CDVA at the last available follow-up was recorded in $1.4 \%$ of eyes (eleven eyes). The reasons for CDVA loss were as follows: nine eyes - ocular surface dryness/superficial punctate keratitis, one eye - age-related macular changes that were not present at the time of enhancement, one eye - traumatic eye injury not related to the enhancement resulting in prolonged corneal edema.

Table 3 shows the pre- and post-enhancement clinical outcomes stratified by the type of pre-enhancement refractive error. Prior to enhancement, $32.5 \%$ of eyes had myopia or myopic astigmatism, $49.2 \%$ of eyes were hyperopic or had hyperopic astigmatism and $18.3 \%$ had mixed astigmatism. All the three categories had significant reduction in sphere, cylinder, and MSE (Table 3). The percentage of patients

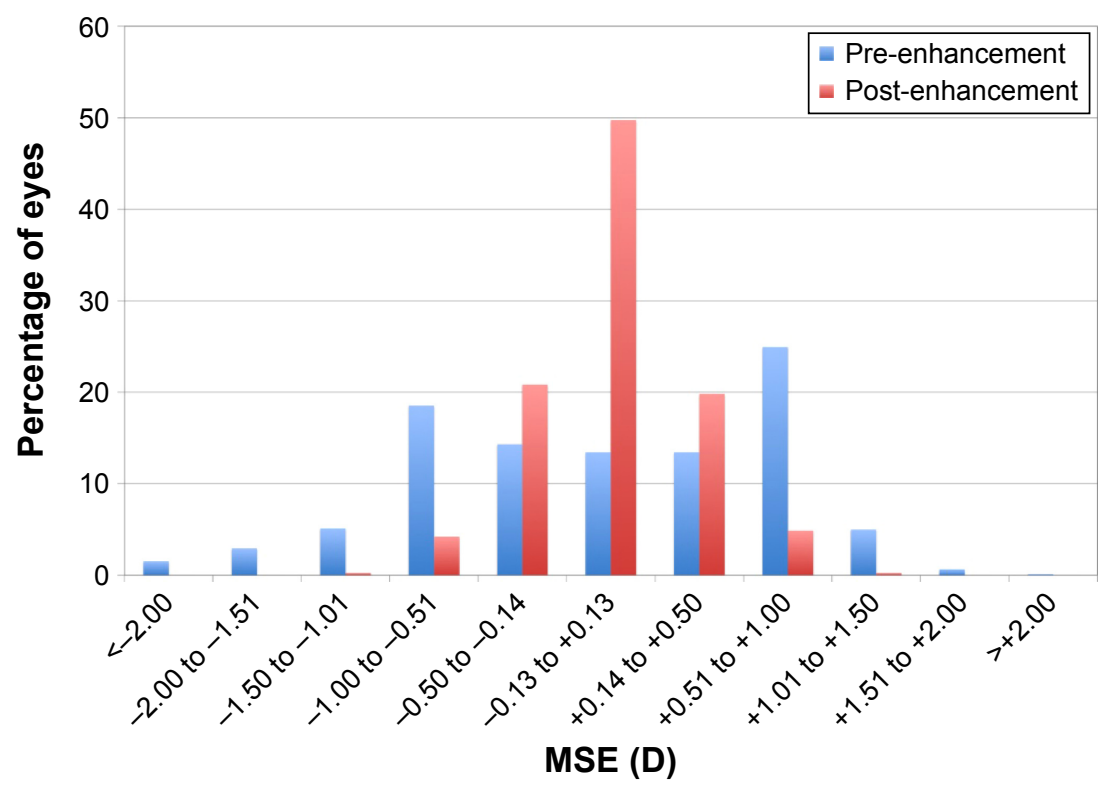

Figure 2 Comparison of pre- and post-enhancement MSE.

Abbreviations: D, diopter; MSE, manifest spherical equivalent. 


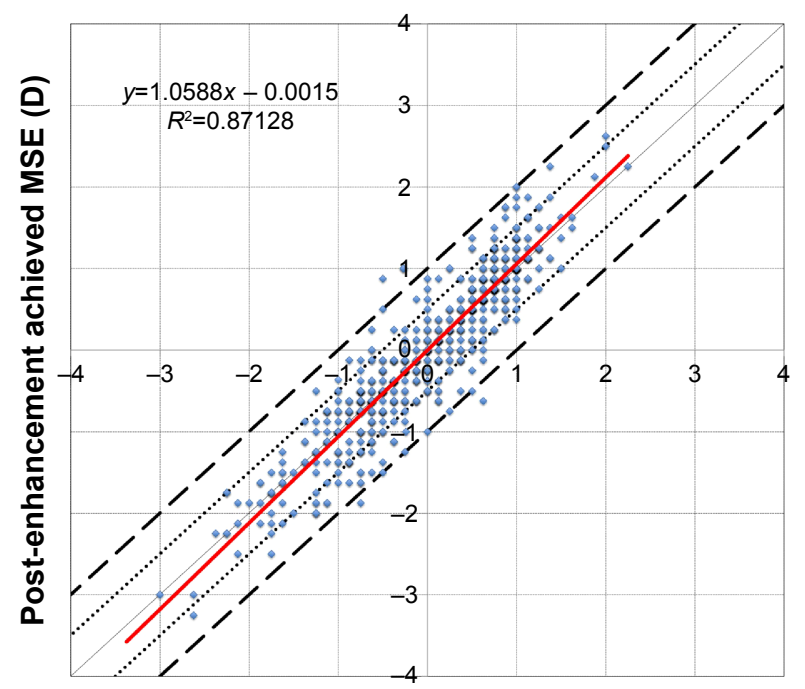

Pre-enhancement attempted MSE (D)

Figure 3 Predictability - scattergram of attempted pre-enhancement MSE correction vs achieved post-enhancement MSE correction.

Notes: Area between two dotted lines represents MSE within $0.50 \mathrm{D}$, and area between dashed lines represents MSE within I.00 D of emmetropia. Solid red line is the linear regression.

Abbreviations: D, diopter; MSE, manifest spherical equivalent.

achieving post-enhancement UDVA $20 / 20$ or better was $71.1 \%$ in the myopic group, $76.4 \%$ in the hyperopic group, and $77.4 \%$ in the mixed astigmatism group.

\section{LASIK vs PRK enhancement}

PRK was performed on 69 eyes and LASIK on 713 eyes. There was no statistically significant difference in pre-enhancement myopic or hyperopic sphere (myopic sphere: PRK, $-0.72 \pm 0.41$ D; LASIK, $-0.73 \pm 0.49$ D; $P=0.85$; hyperopic sphere: PRK, +0.85 \pm 0.49 D; LASIK, +0.82 \pm 0.47 D; $P=0.68)$. Eyes in the PRK group had higher pre-enhancement cylinder (PRK, $-1.03 \pm 0.58 \mathrm{D}$; LASIK, $-0.86 \pm 0.55 \mathrm{D} ; P=0.02$ ) and worse pre-enhancement CDVA (PRK, $-0.02 \pm 0.08$ logMAR [logarithm of the minimum angle of resolution]; LASIK, $-0.04 \pm 0.06 \log$ MAR; $P=0.02$ ).

There was no statistically significant difference in postoperative sphere (PRK, $+0.18 \pm 0.32 \mathrm{D}$; LASIK, $+0.14 \pm 0.35 \mathrm{D}$; $P=0.49$ ), cylinder (PRK, $-0.30 \pm 0.36$ D; LASIK, $-0.29 \pm 0.32 \mathrm{D} ; P=0.81$ ), UDVA (PRK, 0.0 $\pm 0.10 \log \mathrm{MAR}$; LASIK, $0.0 \pm 0.10 \log$ MAR; $P=0.99$ ), or CDVA (PRK, $-0.03 \pm 0.07$ logMAR; LASIK, $-0.04 \pm 0.07$ logMAR; $P=0.53$ ) between the two groups. When evaluating difficulties with post-enhancement dry eye symptoms (measured on scale $1=$ no difficulty to $7=$ severe difficulty; Figure 1 ), the mean score for PRK was $2.2 \pm 1.4$ and for LASIK 2.2 \pm 1.5 $(P=0.89)$.

There was also no statistically significant difference in post-enhancement visual symptoms between the two groups (mean score: starburst: PRK 2.2 \pm 1.4 , LASIK 2.1 \pm 1.5 , $P=0.64$; glare: PRK 1.9 \pm 1.3 , LASIK 2.3 $\pm 1.6 ; P=0.17$, halo: PRK 1.8 \pm 1.3 , LASIK 2.2 $\pm 1.6, P=0.19$; ghosting: PRK $1.8 \pm 1.4$, LASIK $1.9 \pm 1.5, P=0.45)$.

\section{Toric multifocal lenses}

Ninety-four eyes in the study had a toric multifocal IOL implanted during their primary IOL procedure. The mean refractive cylinder in this subgroup of patients was $-1.25 \pm 0.74 \mathrm{D}$ prior to enhancement, and reduced

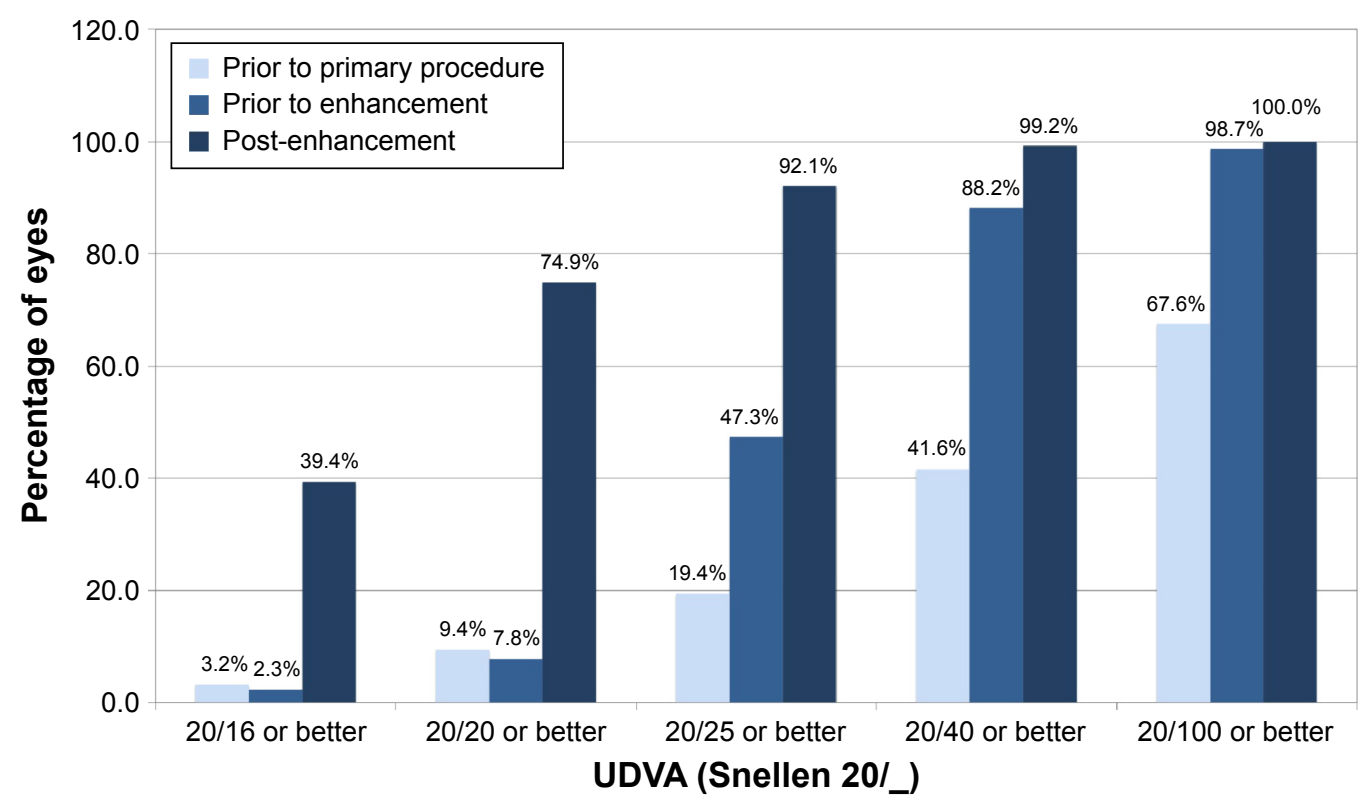

Figure 4 Cumulative monocular UDVA.

Abbreviation: UDVA, uncorrected distance visual acuity. 


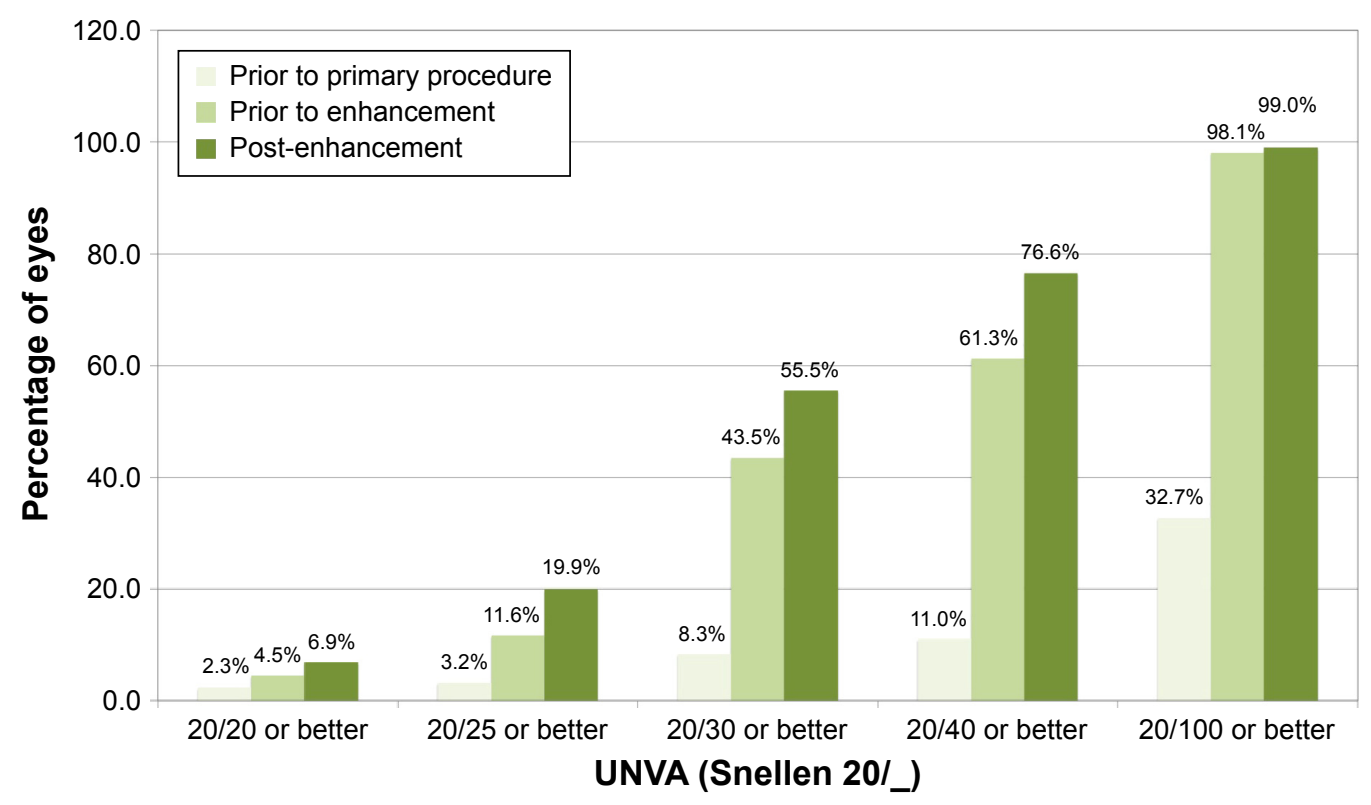

Figure 5 Cumulative monocular UNVA.

Abbreviation: UNVA, uncorrected near visual acuity.

to $-0.23 \pm 0.30 \mathrm{D}(P<0.01)$. There was no statistically significant difference in the residual post-enhancement refractive cylinder in eyes that had a toric IOL and non-toric IOL (mean post-LVC cylinder in patients with non-toric IOL: $-0.30 \pm 0.33 \mathrm{D}, P=0.06$ ).

\section{Complications}

Out of all eyes that had LASIK enhancements ( $n=713$ ), two eyes $(0.3 \%)$ developed peripheral epithelial ingrowth that stabilized and did not affect visual acuity or refraction. Mild diffused lamellar keratitis was observed in 33 eyes (4.6\%), and except for a temporary increase in topical steroid dosing, all resolved without additional intervention. One eye had more severe diffused lamellar keratitis (grade 3) and was successfully treated with increased topical steroids. There was one case of flap striae affecting the patient's CDVA/ quality of vision and a surgical intervention was required. Following a successful flap lift, the patient's CDVA returned

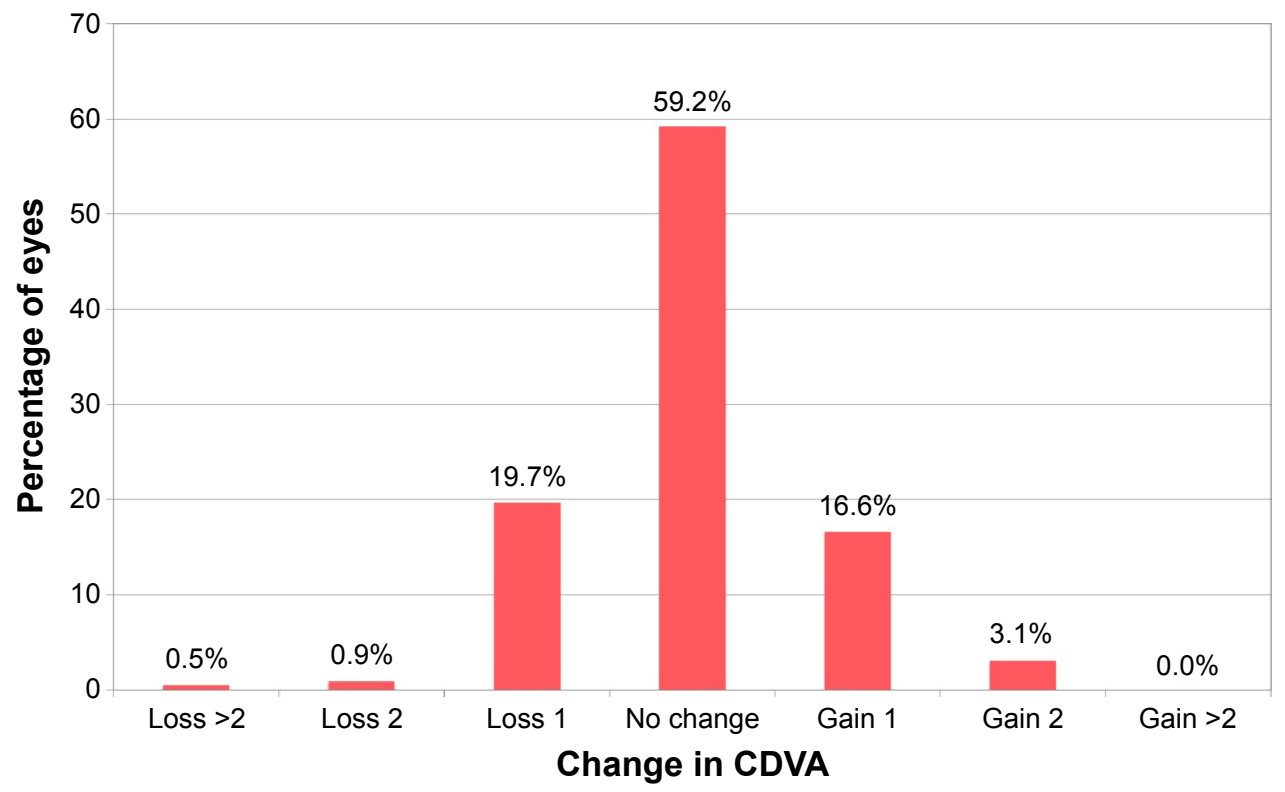

Figure 6 Change in CDVA prior to enhancement to post-enhancement. Abbreviation: CDVA, corrected distance visual acuity. 


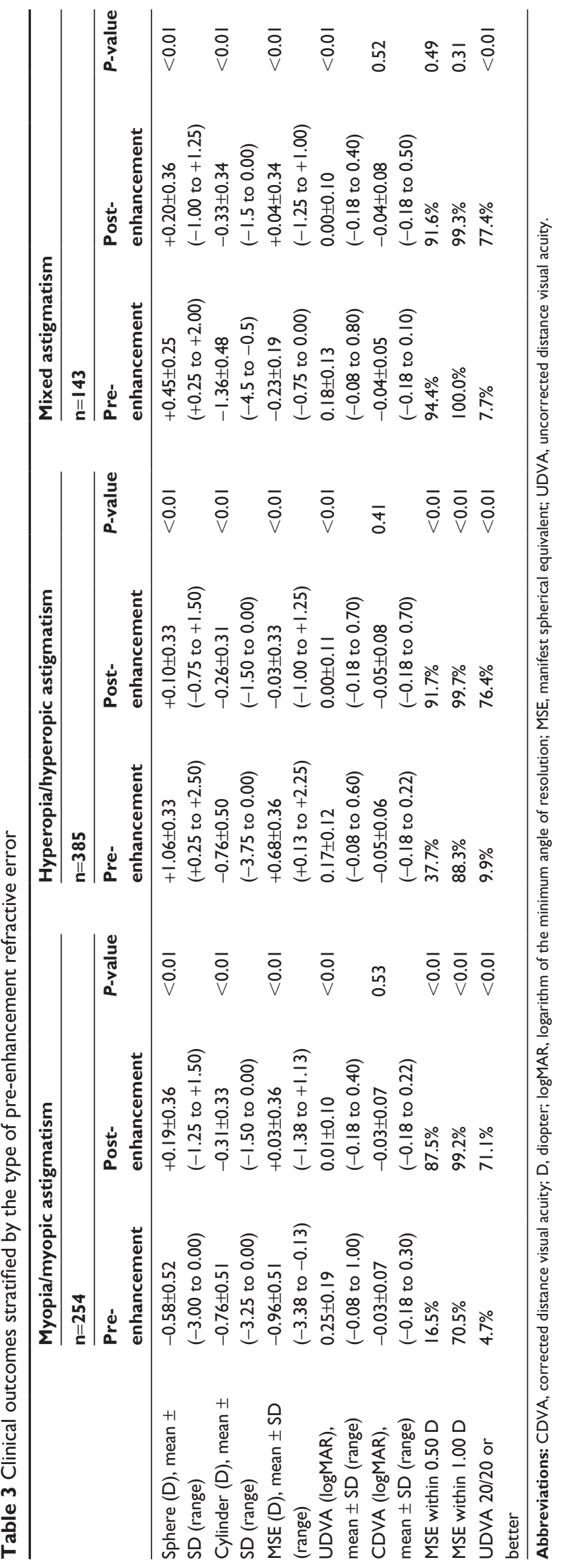

to the preoperative level. In one eye without inflammation or pain, a presumed sterile corneal infiltrate was observed on the first postoperative day. The patient was maintained on his/her broad-spectrum topical antibiotic, and the topical steroid was increased in frequency. The infiltrate resolved within the first 5 postoperative days.

In the group of eyes with surface ablation $(n=69)$, two eyes $(2.9 \%)$ developed mild haze, which cleared within the first 6 postoperative months. There was one case of delayed epithelial healing that required management with therapeutic contact lenses for 1 month and, finally, resolved without any consequence. One patient suffered from recurrent erosion syndrome following the bilateral PRK, which was also managed with therapeutic contact lenses and intense ocular surface lubrication.

\section{Patient-reported outcomes and satisfaction}

Of all patients, $81.3 \%(\mathrm{n}=468)$ completed both pre- and postenhancement questionnaires. The mean patient satisfaction (measured on the scale 1-5; Figure 1) changed from 2.3 \pm 1.1 before enhancement to $1.9 \pm 1.0(P<0.01)$ post-enhancement. The percentage of patients being dissatisfied/very dissatisfied with their vision decreased from $17.0 \%$ prior to enhancement to $9.5 \%$ post-enhancement $(P<0.01)$.

Figure 7 shows the proportion of patients experiencing severe difficulty with night vision phenomena and severe difficulty with tasks requiring distance or near vision. There was a slight improvement in all symptoms from pre- to post-enhancement level, although most of the percentage differences were not statistically significant (Figure 7). The mean change in visual phenomena scores from pre- to post-LVC enhancement (all measured on a scale between $1=$ no difficulty to $7=$ severe difficulty) indicated a slight but statistically significant improvement in all symptoms. The mean score for starburst improved from $2.4 \pm 1.7$ before LVC enhancement to $2.1 \pm 1.5$ ( $P=0.01)$ post-enhancement, and the change in other optical side effects was as follows: glare: $2.5 \pm 1.6$ to $2.2 \pm 1.6, P=0.03$; halo: $2.4 \pm 1.7$ to $2.1 \pm 1.6$, $P=0.03$; ghosting/double vision: $2.2 \pm 1.7$ to $1.9 \pm 1.5, P<0.01$. Overall, there was a slight improvement in visual phenomena symptoms post-enhancement. The mean score for dry eye symptoms changed from $2.0 \pm 1.4$ prior to enhancement to $2.2 \pm 1.5$ post-enhancement $(P=0.06)$.

Out of all clinical parameters, the final satisfaction with visual acuity was most strongly correlated with postoperative monocular UDVA $(r=0.19, P<0.01)$. Post-LVC enhancement satisfaction was also strongly correlated with 


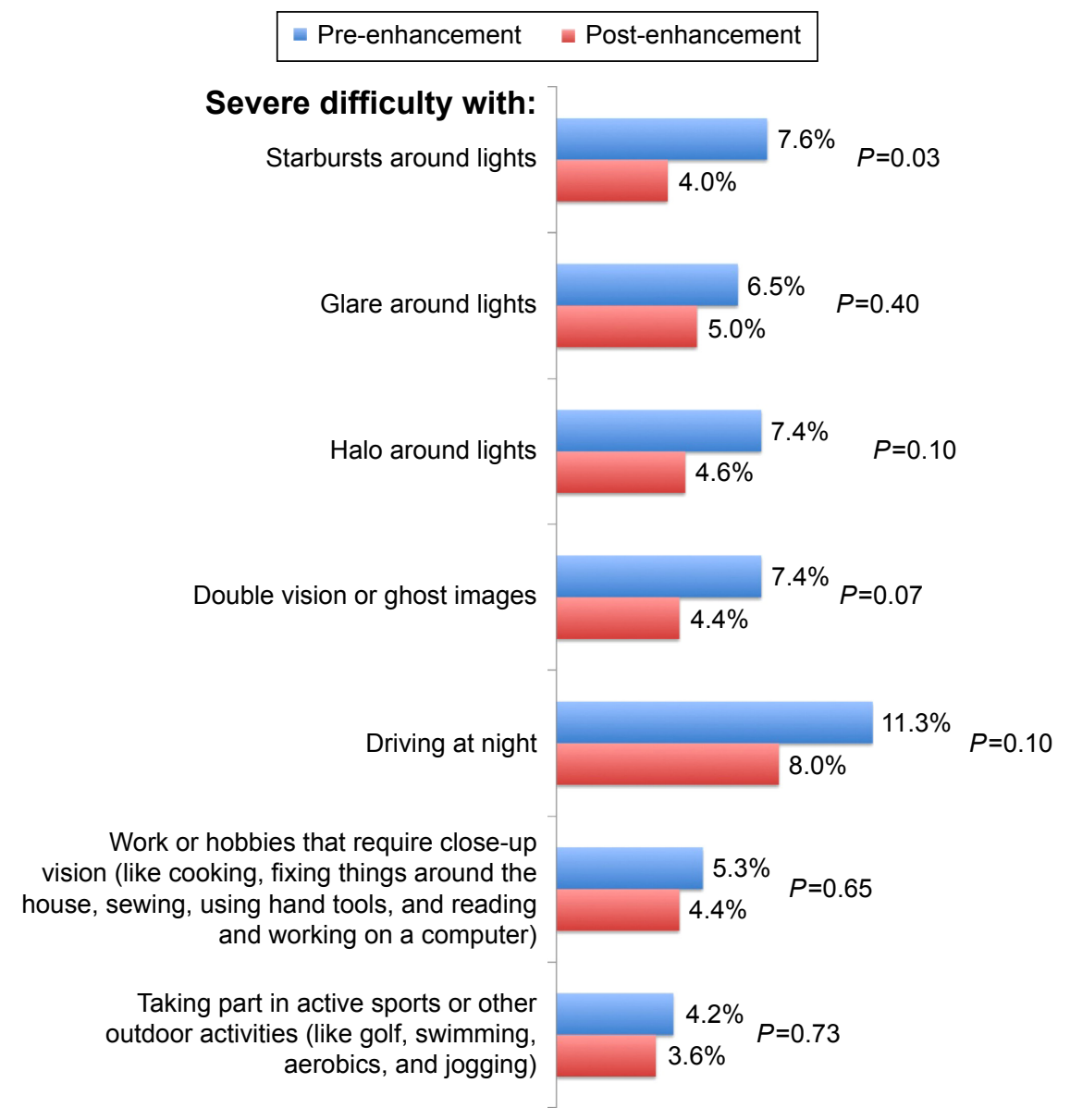

Figure 7 Patient satisfaction questionnaire outcomes.

Notes: Severe difficulty with starburst, glare, halo, ghosting/double vision - percentage of patients who scored 6 or 7 on scale I= no difficulty to $7=$ severe difficulty. Severe difficulty with driving at night, close-up activities, and outdoor activities - percentage of patients who scored "a lot of difficulty" or "never try to do these activities because of my vision". Chi-square test was used to compare percentages.

all the other questionnaire items. For example, the correlation between satisfaction and difficulty with glare postenhancement was $r=0.55(P<0.01)$, and the same applied to all the other ocular side effects (starburst, glare, ghosting/ double vision). It was the final post-LVC enhancement glare (or any other visual phenomena) that affected patient satisfaction more than the change between pre- and post-LVC enhancement glare, which was still significantly correlated with patient satisfaction, but the correlation was weaker ( $r=0.26, P<0.01)$. Despite the pre-enhancement demonstration of visual symptoms in trial frames or with contact lens/ spectacle trial, some patients may have believed that the enhancement would further improve their quality-of-vision issues. It is likely that many of these persistent symptoms were inherent to the multifocal IOL.

The satisfaction was also affected by the difficulty performing tasks such as night driving $(r=0.54, P<0.01)$, close-up activities $(r=0.53, P<0.01)$, and difficulty with outdoor activities $(r=0.44, P<0.01)$. There was a strong relationship between patient satisfaction and the difficulty with dry eye symptoms at the last follow-up $(r=0.50, P<0.01)$.

\section{Discussion}

Despite the use of accurate lens calculation formulas, optimization of A-constants, use of customized toric lenses, and improvements in micro-incision intraocular surgery, undesired postoperative refractive error is still an issue. ${ }^{19-23}$ In a recent retrospective review of $>17,000$ cataract procedures, ${ }^{30}$ emmetropia (defined as spherical equivalent within $\pm 0.50 \mathrm{D}$ with $<1.00 \mathrm{D}$ of astigmatism) was finally achieved only in $55 \%$ of eyes. In our previous series of 9,366 eyes implanted with a nonrotational symmetric lens, ${ }^{31}$ which is the IOL primarily used in the majority of eyes in this study, $91.8 \%$ were within $\pm 1.00 \mathrm{D}$ of MSE at 3 months postoperatively. Although this refractive predictability was good, it also indicates that a not-insignificant fraction of these patients would require additional procedures to achieve emmetropia. Variables routinely measured before 
cataract surgery (such as age, refraction, axial length, and intraocular pressure) cannot accurately predict the need for LVC enhancement. ${ }^{32}$

In the current study, $90.4 \%$ of eyes were within $0.50 \mathrm{D}$ and $99.5 \%$ within $1.00 \mathrm{D}$ of emmetropia following the laser enhancement. Only $7.8 \%$ of patients had UDVA 20/20 or better prior to enhancement, and this number increased to $74.9 \%$ post-enhancement. The mean CDVA was almost the same before $(-0.04 \pm 0.06 \log$ MAR $)$ and after enhancement $(-0.04 \pm 0.07 \log$ MAR $)$. The symptoms of photic phenomena slightly reduced following the enhancement (Figure 7), but they did not completely disappear, which is expected with the use of multifocal lens designs.

There are several reasons why results of laser enhancements in pseudophakic patients could be different from primary laser patients. Patients with cataract are typically 2 to 3 decades older, and older age can be associated with lower predictability and efficacy of excimer ablation, ${ }^{33,34}$ as well as higher susceptibility to tear-film deficiency. ${ }^{35}$ The pseudophakic patients typically have one or two corneal incisions, as well as additional incisions to correct astigmatism. It is possible that these incisions could be slightly distorted during suction required for the creation of LASIK flap and affect postoperative outcomes. ${ }^{12,23}$ Despite these potential concerns, excellent outcomes have been reported with the use of excimer laser ablation in pseudophakic patients, ${ }^{7-18}$ and it remains the preferred surgical option for unintended ametropia. ${ }^{19-23}$ Predictability was confirmed in many studies in patients with monofocal IOL; ${ }^{7-10,12,16}$ however, to our knowledge, only a few studies have been previously published on the use of excimer laser surgery in patients with a multifocal lens. ${ }^{11,13-17}$

In the first report, Leccisotti ${ }^{11}$ presented outcomes of 18 eyes that had PRK for residual refractive error after the implantation of Array SA40N refractive IOL (AMO, Inc., Santa Ana, CA, USA). Postoperative spherical equivalent was slightly hyperopic (+0.33 D), with the mean postoperative UDVA of $0.8(=0.1 \log$ MAR). Fifteen eyes $(83 \%)$ were within $0.50 \mathrm{D}$ of emmetropia. The study concluded that PRK significantly improved visual acuity, but it had limited effect on halos associated with Array lens and some patients eventually required an exchange to a monofocal lens.

Alfonso et $\mathrm{al}^{14}$ presented outcomes of 53 eyes that underwent LASIK for residual ametropia after the implantation of AcrySof ReSTOR (Alcon, Inc., Hünenberg, Switzerland) apodized diffractive IOL, using conventional ablation profile and femtosecond laser for flap creation. Excellent outcomes were achieved in terms of predictability: all eyes were within $\pm 1.00 \mathrm{D}$ and $96.2 \%$ were within $\pm 0.50 \mathrm{D}$ of the desired refraction. This is slightly superior to our outcomes, but a much lower range of refractions was treated in this study (pre-enhancement MSE: $-2.00 \mathrm{D}$ to $+1.00 \mathrm{D}$, compared to the MSE of the current study, ranging between $-3.38 \mathrm{D}$ and +2.25 D). Six months after LASIK, the mean UDVA was $0.83 \pm 0.20(\approx 0.08 \log$ MAR).

In 2008 , Jendritza et al ${ }^{13}$ published outcomes of 27 pseudophakic eyes treated with WFG LASIK. Twenty-four eyes had a diffractive multifocal IOL (Tecnis; Abbott Medical Optics Inc., or ReSTOR), and four eyes had a refractive IOL (ReZoom; Abbott Medical Optics Inc.). The conclusion was that WFG LASIK could successfully treat residual ametropia in patients with multifocal lens implant, but it did not improve higher-order aberrations. The authors advised against the use of WFG ablation in patients with refractive IOLs, as the measurements with wavefront sensors may not be reliable. WFG LASIK in eyes with diffractive IOLs did not affect multifocality of the lens, and the patients retained about the same corrected near and distance visual acuity following the excimer laser ablation. On the other hand, in the group of patients with a refractive IOL, there was one-line loss of distance corrected and two lines loss of near corrected visual acuity. However, these conclusions were based only on four eyes included in this subcategory. The majority of patients in our study (98.7\%) had an IOL with refractive design, and there was no loss in the mean CDVA.

Muftuoglu et $\mathrm{al}^{15}$ retrospectively studied 85 eyes with apodized diffractive IOL, which were enhanced for residual myopia, hyperopia, or mixed astigmatism. Of the whole cohort, $15 \%$ of eyes had WFG ablation. Pre-enhancement spherical equivalent ranged between $-2.58 \mathrm{D}$ and $+1.63 \mathrm{D}$ and postoperatively, $96 \%$ and $99 \%$ of eyes were within $0.50 \mathrm{D}$ and $1.00 \mathrm{D}$ of targeted refraction. Postoperative mean UDVA was 0.05 $\pm 0.08 \log$ MAR, and there was no difference in achieved UDVA between eyes with preoperative myopia, hyperopia, and mixed astigmatism. This is comparable to our outcomes, where UDVA was very close to $20 / 20$ (0.0 logMAR) in all the three subcategories (Table 3).

Piñero et $\mathrm{al}^{16}$ compared the outcomes of LASIK for pseudophakic ametropia in eyes with monofocal IOL and multifocal IOL with 50 eyes in each group. Of all eyes, $84 \%$ were within $0.50 \mathrm{D}$ of emmetropia in the monofocal group and $70 \%$ in the multifocal group, and this difference was not statistically significant. Postoperative UDVA was similar in both the groups $(0.15 \pm 0.18 \log$ MAR in the multifocal group, $0.14 \pm 0.11 \log$ MAR in the monofocal group). When examining eyes with multifocal IOL, no difference in postoperative 
outcomes was found between eyes with diffractive and refractive lenses. The authors further divided the eyes with multifocal IOLs into those that had hyperopic and those with myopic pre-enhancement refractive error, and they concluded that eyes with hyperopic error had less predictable outcomes. Eyes with preoperative hyperopia had tendency for undercorrection, and there was a higher variability in postoperative MSE $(+0.32 \pm 0.72 \mathrm{D})$, whereas eyes with preoperative myopia were slightly overcorrected, but the standard deviation of postoperative MSE was lower (+0.28 $\pm 0.45 \mathrm{D})$. This was attributed to the difficulties in estimating refractive error in patients with multifocal IOL caused by the presence of several foci, which can result in artifacts in subjective refraction due to several refractive options providing similar visual quality. They recommended the use of the midpoint refraction of the clear vision interval provided by the depth of field of the IOL to avoid postoperative problems of predictability. In contrast, Albarrán-Diego et a ${ }^{17}$ describe difficulty in treating pseudophakic patients with multifocal IOL with myopic residual refraction. However, this study is only a case report of three eyes with unexpected hyperopic surprise.

The findings of our study did not confirm those of Piñero et al. ${ }^{16}$ Eyes with preoperative myopia or hyperopia had both predictable outcomes with the mean postoperative spherical equivalent close to emmetropia, with very similar standard deviation (myopic eyes: $+0.04 \pm 0.36 \mathrm{D}, \mathrm{n}=254$; hyperopic eyes: $-0.03 \pm 0.33, n=385$ ). The percentage of eyes within $0.50 \mathrm{D}$ of targeted refraction was actually slightly higher in patients with preoperative hyperopia $(91.7 \%)$ than those with myopic error (87.5\%; Table 3), although this difference was not statistically significant. One possible explanation could be careful pre-enhancement counseling and examination. Patients with slight hyperopic error are mostly affected by inability to see well close-up, but they often have very good distance visual acuity. Thus, contact lens or spectacle trial is often necessary to ensure that the patient will benefit from enhancement and that postoperative overall visual acuity will not be affected. The refraction determined from this trial is then used in preoperative planning.

In this study, LASIK was the preferred choice for the enhancement of pseudophakic ametropia, which was performed in $91.3 \%$ of eyes. Although the group of patients with surface ablation was much smaller, there was no statistically significant difference in any of the postoperative clinical parameters between the two techniques. LASIK is a popular choice due to its fast and relatively pain-free recovery; however, there could be an increased risk of dry eye symptoms with the creation of the corneal flap, especially in a group of older patients who are more prone to tear-film abnormalities. Despite this concern, we did not find a statistically significant difference in postoperative dry eye symptoms between the two techniques. Both enhancement methods might potentially have increased complication rates related to older age. Surface ablation might require longer re-epithelialization period due to the age-related decrease in the healing response, ${ }^{36,37}$ which was observed only in one case in this study. On the other hand, the creation of LASIK flap temporarily increases intraocular pressure, which could result in complications associated with posterior segment of the eye, ${ }^{38}$ such as retinal detachment, macular hemorrhage, damage to optic nerve, and visual field defect. We did not see any vitreoretinal complications related to LASIK in our cohort of 724 eyes. However, our patients were younger ( $57.4 \pm 7.2$ years) than a typical population of patients undergoing cataract surgery. In addition, patients with posterior segment pathology were excluded during preoperative screening as this would be a contraindication to multifocal IOL implantation.

\section{Conclusion}

Our study had several limitations. Although there were a large number of patients involved, the study was retrospective and there was a variation in the time between the enhancement and the last postoperative visit. Thus, we could not calculate the stability of outcomes over the period of time. Despite this, findings of this study confirmed that excimer ablation can be safely and successfully utilized in eyes with multifocal lens and undesired pseudophakic ametropia. Due to the age of this population, patients should be carefully counseled for possible increase in dry eye symptoms, and some of the undesired optical side effects might remain despite the successful correction of refractive error.

\section{Disclosure}

Steven C Schallhorn, MD, is a consultant for Abbott Medical Optics Inc., Carl Zeiss Meditec AG, and AcuFocus Inc., Irvine, CA, USA, and a global medical director for Optical Express. The authors have no other conflicts of interest in this work.

\section{References}

1. Erickson P. Effects of intraocular lens position errors on postoperative refractive error. J Cataract Refract Surg. 1990;16:305-311.

2. Norrby S. Sources of error in intraocular lens power calculation. J Cataract Refract Surg. 2008;34:368-376.

3. Pierro L, Modorati G, Brancato R. Clinical variability in keratometry, ultrasound biometry measurements, and emmetropic intraocular lens power calculation. J Cataract Refract Surg. 1991;17:91-94.

4. Narváez J, Zimmerman G, Stulting RD, Chang DH. Accuracy of intraocular lens power prediction using the Hoffer Q, Holladay 1, Holladay 2, and SRK/T formulas. J Cataract Refract Surg. 2006;32:2050-2053. 
5. Høvding G, Natvik C, Sletteberg O. The refractive error after implantation of a posterior chamber intraocular lens. The accuracy of IOL power calculation in a hospital practice. Acta Ophthalmol (Copenh). 1994;72:612-616.

6. Raman S, Redmond R. Reasons for secondary surgical intervention after phacoemulsification with posterior chamber lens implantation. J Cataract Refract Surg. 2003;29:513-517.

7. Artola A, Ayala MJ, Claramonte P, Pérez-Santonja JJ, Alió JL. Photorefractive keratectomy for residual myopia after cataract surgery. J Cataract Refract Surg. 1999;25(11):1456-1460.

8. Pop M, Payette Y, Amyot M. Clear lens extraction with intraocular lens followed by photorefractive keratectomy or laser in situ keratomileusis. Ophthalmology. 2001;108(1):104-111.

9. Velarde JI, Anton PG, de Valentin-Gamazo L. Intraocular lens implantation and laser in situ keratomileusis (bioptics) to correct high myopia and hyperopia with astigmatism. J Refract Surg. 2001;17(2 suppl): S234-S237.

10. Zaldivar R, Oscherow S, Piezzi V. Bioptics in phakic and pseudophakic intraocular lens with the Nidek EC-5000 excimer laser. J Refract Surg. 2002;18(3 suppl):S336-S339.

11. Leccisotti A. Secondary procedures after presbyopic lens exchange. J Cataract Refract Surg. 2004;30(7):1461-1465.

12. Kuo IC, O'Brien TP, Broman AT, Ghajarnia M, Jabbur NS. Excimer laser surgery for correction of ametropia after cataract surgery. J Cataract Refract Surg. 2005;31(11):2104-2110.

13. Jendritza BB, Knorz MC, Morton S. Wavefront-guided excimer laser vision correction after multifocal IOL implantation. J Refract Surg. 2008;24(3):274-279.

14. Alfonso JF, Fernández-Vega L, Montés-Micó R, Valcárcel B. Femtosecond laser for residual refractive error correction after refractive lens exchange with multifocal intraocular lens implantation. Am J Ophthalmol. 2008;146:244-250.

15. Muftuoglu O, Prasher P, Chu C, et al. Laser in situ keratomileusis for residual refractive errors after apodized diffractive multifocal intraocular lens implantation. J Cataract Refract Surg. 2009;35(6):1063-1071.

16. Piñero DR, Ayala Espinosa MJ, Alió JL. LASIK outcomes following multifocal and monofocal intraocular lens implantation. J Refract Surg. 2010;26(8):569-577.

17. Albarrán-Diego C, Muñoz G, Ferrer-Blasco T, García-Lázaro S. Prevention of hyperopic surprise after LASIK in patients with refractive multifocal intraocular lenses. Eur J Ophthalmol. 2011;21(6):826-829.

18. Jin GJ, Merkley KH, Crandall AS, Jones YJ. Laser in situ keratomileusis versus lens-based surgery for correcting residual refractive error after cataract surgery. J Cataract Refract Surg. 2008;34(4):562-569.

19. Moshirfar M, McCaughey MV, Santiago-Caban L. Corrective techniques and future directions for treatment of residual refractive error following cataract surgery. Expert Rev Ophthalmol. 2014;9(6):529-537.

20. Fernández-Buenaga R, Alió JL, Pérez Ardoy AL, Quesada AL, PinillaCortés L, Barraquer RI. Resolving refractive error after cataract surgery: IOL exchange, piggyback lens, or LASIK. J Refract Surg. 2013; 29(10):676-683.

21. Alio JL, Abdelghany AA, Fernández-Buenaga R. Management of residual refractive error after cataract surgery. Curr Opin Ophthalmol. 2014;25(4):291-297.

22. Alio JL, Abdelghany AA, Fernández-Buenaga R. Enhancements after cataract surgery. Curr Opin Ophthalmol. 2015;26(1):50-55.

Clinical Ophthalmology

\section{Publish your work in this journal}

Clinical Ophthalmology is an international, peer-reviewed journal covering all subspecialties within ophthalmology. Key topics include: Optometry; Visual science; Pharmacology and drug therapy in eye diseases; Basic Sciences; Primary and Secondary eye care; Patient Safety and Quality of Care Improvements. This journal is indexed on Submit your manuscript here: http://www.dovepress.com/clinical-ophthalmology-journal
23. Sáles CS, Manche EE. Managing residual refractive error after cataract surgery. J Cataract Refract Surg. 2015;41(6):1289-1299.

24. Woodward M, Randleman B, Stulting D. Dissatisfaction after multifocal intraocular lens implantation. J Cataract Refract Surg. 2009; 35:992-997.

25. Zheleznyak L, Kim MJ, MacRae S, Yoon G. Impact of corneal aberrations on through-focus image quality of presbyopia-correcting intraocular lenses using an adaptive optics bench system. J Cataract Refract Surg. 2012;38:1724-1733.

26. Muñoz G, Albarrán-Diego C, Sakla HF. Validity of autorefraction after cataract surgery with multifocal ReZoom intraocular lens implantation. J Cataract Refract Surg. 2007;33:1573-1578.

27. Charman WN, Montés-Micó R, Radhakrishnan H. Problems in the measurement of wavefront aberration for eyes implanted with diffractive bifocal and multifocal intraocular lenses. J Refract Surg. 2008;24: 280-286.

28. Campbell CE. Wavefront measurements of diffractive and refractive multifocal intraocular lenses in an artificial eye. J Refract Surg. 2008; 24:308-311.

29. Solomon KD, Fernández de Castro LE, Sandoval HP, et al; Joint LASIK Study Task Force. LASIK world literature review: quality of life and patient satisfaction. Ophthalmology. 2009;116(4):691-701.

30. Behndig A, Montan P, Stenevi U, Kugelberg M, Zetterström C, Lundström M. Aiming for emmetropia after cataract surgery: Swedish National Cataract Register study. J Cataract Refract Surg. 2012;38: 1181-1186.

31. Venter JA, Pelouskova M, Collins BM, Schallhorn SC, Hannan SJ. Visual outcomes and patient satisfaction in 9366 eyes using a refractive segmented multifocal intraocular lens. J Cataract Refract Surg. 2013; 39(10):1477-1484.

32. Gunvant P, Ablamowicz A, Gollamudi S. Predicting the necessity of LASIK enhancement after cataract surgery in patients with multifocal IOL implantation. Clin Ophthalmol. 2011;5:1281-1285.

33. Ghanem RC, de la Cruz J, Tobaigy FM, Ang LPK, Azar DT. LASIK in the presbyopic age group; safety, efficacy, and predictability in 40- to 69-year-old patients. Ophthalmology. 2007;114:1303-1310.

34. Hu DJ, Feder RS, Basti S, et al. Predictive formula for calculating the probability of LASIK enhancement. J Cataract Refract Surg. 2004;30: 363-368.

35. Battat L, Macri A, Dursun D, Pflugfelder SC. Effects of laser in situ keratomileusis on tear production, clearance, and the ocular surface. Ophthalmology. 2001;108:1230-1235.

36. Hersh PS, Schein OD, Steinert R. Characteristics influencing outcomes of excimer laser photorefractive keratectomy. Summit Photorefractive Keratectomy Phase III Study Group. Ophthalmology. 1996;103(11): 1962-1969.

37. Detorakis ET, Siganos DS, Kozobolis VP, Pallikaris IG. Corneal epithelial wound healing after excimer laser photorefractive and photoastigmatic keratectomy (PRK and PARK). Cornea. 1999;18(1): 25-28.

38. Mirshahi A, Baatz H. Posterior segment complications of laser in situ keratomileusis (LASIK). Surv Ophthalmol. 2009;54(4):433-440.
PubMed Central and CAS, and is the official journal of The Society of Clinical Ophthalmology (SCO). The manuscript management system is completely online and includes a very quick and fair peer-review system, which is all easy to use. Visit http://www.dovepress.com/ testimonials.php to read real quotes from published authors. 